\title{
Appraisals, Coping and Affective and Behavioral Reactions to Academic Stressors
}

\author{
Hasida Ben-Zur, Moshe Zeidner \\ University of Haifa, Haifa, Israel \\ Email: zbz@netvision.net.il
}

Received June $3^{\text {rd }}, 2012$; revised July $5^{\text {th }}, 2012$; accepted August $3^{\text {rd }}, 2012$

\begin{abstract}
This study, based on the cognitive model of stress (Lazarus, 1999), examined 294 Jewish and 234 Arab students' stress appraisals, coping strategies, and emotional and behavioral reactions to academic stressors. Perceived stress was positively related to emotion/support and avoidance coping, which, in turn, were related to high negative affect and risk taking. The findings suggest interventions among students to aid them to successfully adapt to academic stress.
\end{abstract}

Keywords: Academic Stressor; Coping; Negative Affect; Risk Taking; Jewish/Arab Cultural Groups

\section{Introduction}

This study is theoretically grounded in the cognitive model of stress (Lazarus, 1999; Lazarus \& Folkman, 1984) and sets out to assess key facets of the stress and coping process in the academic context. The major aim of the study is to assess stress appraisals, coping strategies, and emotional and behavioral outcomes (i.e., negative affect and risk-taking, respectively) in response to a salient academic stressor. Additionally, we aimed to compare Jewish and Arab students on stress and coping factors.

\section{Academic Stress}

Academic stress refers to those environmental demands and challenges in an academic setting (e.g., meeting deadlines for assignments, exams, social relations, etc.) that tax, challenge, or exceed a students' coping resources, and represent a "call for action". The degree of stress experienced by a student in an academic situation may depend on a wide array of factors, including the objective properties of the academic environment (academic standards of excellence, course difficulty, etc.), the individual's perception of the academic environment (perceived competitiveness, perceived social support, etc.), perceived coping resources (cognitive, social, emotional, physical, spiritual), available arsenal of coping strategies for transacting with environmental stressors, and the specific cultural lens through which the environmental demands are experienced.

Evaluative stress is a major component of academic stress and a ubiquitous source of stress for students across the globe (Zeidner, 1998). College students are required to adjust to a variety of challenging situational demands, including the unique demands of the academic curriculum and instructional system, to assimilate vast amounts of academic material under stringent time constraints, and cope with the demands and pressures of coursework assignments and final exam period. In addition, students need to make necessary adjustment to their social milieu and learn to conform to the campus subculture and social network. Furthermore, most students, in their late teens to mid twenties, face the psychological developmental stage challenges and life tasks characteristic of late adolescence and the transition into young adulthood, and are also exposed to many normative lire events. Work, social relations, familial responsibilities, hobbies, professional interests, and cultural backgrounds often place constraint on students' degree of freedom, draining student time resources, and plunging students into within-role conflicts (e.g., academic vs work or social demands) which many may find difficult to resolve. The need to negotiate a multitude of environmental demands may severely tax and exceed the coping capacities of many, often leading to increased feelings of frustration and anxiety, problems of adjustment and to depressed student performance (Zeidner \& Schwarzer, 1996).

\section{Stress and Coping: The Transactional Perspective}

Psychological stress is frequently described as the "Black Plague" of the modern era, taxing the resources of individuals and threatening individuals' well-being and societal health. From a transactional perspective (Lazarus \& Folkman, 1984), stress is conceptualized as a dynamic process or "transaction" between the individual and various facets of the environment that are perceived to tax, threaten, or to exceed a person's resources and coping capabilities and endangering the person's sense of well-being (Lazarus, 1999; Lazarus \& Folkman, 1984). Thus, in order to understand a stressful experience one must consider both the subjective milieu (appraisals, values, commitments, beliefs, cognitions) and objective environments (e.g., familial, learning, occupational, community) impinging on the person, along with stable individual differences or background factors that influence perceptions of both the nature and strength of environmental stressors.

The cognitive, transactional model emphasizes the crucial role of situations, but generally views them as informational inputs whose behavioral impact depends on how they are processed by the person. Accordingly, the judgment that a particular person-environment relationship is stressful depends largely on cognitive appraisals - the individual's evaluation of the personal significance of ongoing events and his or her capacity to react to them. For example, a person who perceives an aca- 
demic situation as personally threatening or harmful to her well-being will experience an increase in stress-related emotions, irrespective of the presence of real or objective threat.

According to a transactional perspective, coping involves a person's efforts - cognitive and behavioral - to manage (i.e., reduce, minimize, master, tolerate) both the external and internal demands of a person-environment transaction that is appraised as stressful (Lazarus, 1999; Lazarus \& Folkman, 1984). Although a wide array of taxonomies of coping strategies are currently available, the literature has converged on the following three categories: a) Problem-focused coping, designed to manage or solve the problem by removing or circumventing the stressor (e.g., carefully planning for a major presentation before one's seminar class); b) Emotion-focused coping, designed to regulate, reduce, channel, or eliminate the aversive emotions associated with the stressful encounter (e.g., seeking emotional support from friends, denying the importance of the event); and c) Avoidance-focused coping, referring to strategies designed to circumvent or avoid the stressful situation, either via use of person-oriented strategies (e.g., distracting oneself by socializing with others) or task-oriented strategies (e.g., taking a holiday, as avoidant strategy).

Overall, adaptive coping with stress should lead to positive outcomes, such as heightened satisfaction, fewer psychosomatic symptoms, and decreased anxiety. In contradistinction, the stress process, if not adaptively handled, may contribute to a wide range of physical and mental disorders, including: anxiety, depression, cardiovascular disease, chronic respiratory ailments, infectious disease, and cancer (e.g., Penley, Tomaka, \& Wiebe, 2002; Zeidner, 1998).

A number of past studies have investigated the processes involved in coping with a specific stressor, namely, examination stress (e.g., Carver et al., 1989; Folkman \& Lazarus, 1985; Zeidner, 1995). For example, Zeidner (1995) showed that situational emotion-focused coping was related positively to state anxiety whereas problem-focused coping predicted midterm examination grades. Another study by Struthers, Perry and Menec (2000) showed that problem-focused and emotion-focused coping styles were positively related to perceived stress associated with introductory psychology course, and problem-focused coping mediated its effects on college students' motivation which was positively related to academic grades, and similarly, in a recent study (Saklofske, Austin, Mastoras, Beaton, \& Osborne, 2012) task-oriented coping was related positively to students' grades.

The present study focused on a variety of academic stressors, with the aim of assessing the ways Jewish and Arab students perceived and coped with these stressors and the adaptive value of coping strategies in terms of emotional and behavioral outcomes.

\section{Cultural Group Differences in Stress, Coping, and Adaptive Outcomes}

Israel is a pluralistic society, comprised of myriad ethnic, cultural, and religious subgroups. At present, close to $80 \%$ of its population is of Jewish extraction and the remainder of the population is comprised of a wide array of religious, cultural, and ethnic groups (Muslims, Druze, Christians, etc.). Arabs are a minority group in Israel, comprising slightly over $20 \%$ of the total population and numbering close to $1,600,000$ million people (CBS Press Release, 2011). As reported by Habib (2008), over $80 \%$ of Arab Israelis are of Muslim denomination, with the remainder of Christian (about 10\%) and Druze (about 8\%) The co-existence of two culturally distinct populations-Arabs and Jews - in Israel provides an invaluable opportunity for the investigation of cultural influences on the stress and coping process.

In contrast to the modern individualistic values endorsed by the majority of Israeli Jews, traditional collectivistic values and norms are commonly held to be part and parcel of the overall collective societal experience of Israeli Arabs (Dwairy, 2006). Israelis have adopted behavioral norms which characterize a Western society and tend to focus on self-fulfillment to promote their individual goals (Oyserman, Coon, \& Kemmelmeier, 2002). In contrast, Arabs in Israel are a relatively collectivistcommunal, homogeneous cultural group, characterized by collectivistic tendencies (maintaining group membership, harmonious relations with others, etc.), and more authoritarian parenting (Dwairy, 2004).The bulk of the research on cultural group effects in Israel has been based on the individualismcollectivism paradigm (Gelhaar et al., 2007). Overall, this research suggests that Israelis are closer to the individualistic pole, whereas Arabs are closer to the collectivistic pole.

Arabs in Israel are in a disadvantaged position when it comes to education, employment, social welfare, and health care (Kamm, 2003). Furthermore, Arabs and Jews attend parallel school systems with different curricula, languages of study, school hours, and quality of education. Inequality in government allocations for infrastructure and improvement (Khamaisi, 2011) has led to widespread underdevelopment and insufficient support for the Arab educational system, which, in turn, has contributed to lower levels of educational achievement and professional training. As a whole, Arab children perform below Jewish children in school, with higher dropout rates by age 17 , lower success rates on matriculation tests, and lower mean college entrance exam scores (Habib, 2008; Kamm, 2003; Zeidner, 1987). Indeed, Arab youth and adults report higher rates of psychological stress (depression, sleep problems) and greater difficulties in coping with problems of daily life compared to their Jewish counterparts (Habib, 2008).

Relatively few studies have compared Arab and Jewish students in their coping with more mundane or routine stressors. A study by Zeidner (1992) found that first year Arab students reported significantly higher levels of overall academic stress relative to their Jewish counterparts, with cultural background accounting for about $16 \%$ of the total stress score variance. However, academic stress was not explored in relation to coping strategies or adaptive outcomes.

\section{The Present Study}

Following the cognitive model of stress and coping (Lazarus, 1999), the main aim of the study is to assess the interrelationships between stress appraisals, coping strategies, and their emotional and behavioral outcomes. The hypotheses were: a) Appraisals of stress with respect to an academic stressor would be inversely related to problem-focused coping and positively related to less adaptive coping strategies (emotion-focused, avoidance); b) Stress appraisals and less adaptive coping strategies would be positively related to less adaptive outcomes, that is, negative affect and risk taking behavior.

Negative affect has been extensively studied in relation to coping with stressful encounters (e.g., Ben-Zur \& Debi, 2005; 
Ben-Zur, Yagil, \& Oz, 2005; Gaudreau, Blondin, \& Lapierre, 2002; Lowe, Norman, \& Bennett, 2000; Ntoumanis \& Biddle, 1998). Risk taking behavior has also been studied as an outcome of traumatic encounters and as a correlate of PTSD (see review by Ben-Zur \& Zeidner, 2009). The present study assessed negative affect and risk taking as a possible outcome of encountering and coping with academic stress.

A secondary aim of the study is to assess the extent to which cultural group membership (i.e., Arabs vs Jews) affects stress appraisals, coping strategies, and adaptive outcomes. Different facets of the academic environment may be differentially perceived, interpreted, and responded to as a function of sociocultural group membership. Furthermore, Arab students are members of a disadvantaged cultural minority group in Israeli society, with lower average socioeconomic background and national dissatisfaction. The third hypothesis was: c) Compared with Jewish students, Arab students would show increased stress appraisals, less adaptive coping strategies, and less adaptive outcomes when retrospectively considering a common source of routine stress, i.e., academic stressors.

\section{Method}

\section{Participants and Procedure}

294 Jewish and 234 Arab students enrolled at a large research university in Northern Israel participated in this study. The student body at this university is comprised of $80 \%$ Jewish and $20 \%$ Arab students; this university caters to the majority of Arab university students in Israel. Respondents were about evenly divided by gender ( $53 \%$ females), with a mean age of $25.84(\mathrm{SD}=4.47$, range $19-40)$. The majority of the student participants were Israeli born $(90 \%)$, undergraduates, (78\%), and single $(65 \%)$. Overall, students evaluated their economic status as slightly below average $(1=$ very good; 5 = very bad; $\mathrm{M}=2.67$; $\mathrm{SD}=.98$ ).

Table 1 presents demographic characteristics, separately for Arab and Jewish student groups. As shown in Table 1, Arab participants were younger, on average, than their Jewish counterparts. This presumably stems from the fact that the vast majority of Arab students (Moslem and Christians) can enroll at the university at a younger age than Jewish students, as they are not required to enlist in the Israeli army for compulsory military service. Also, based on parental education and self-appraised economic status, Arab participants were reported to be of lower socio-economic status than Jewish students.

The assessment packets were distributed to students, on the basis of convenience. The respondents were informed that the measures included items related to individual differences in attitudes, feelings, and cognitions, and were assured that their responses would be coded anonymously. The research was approved by the institution's human subject committee.

\section{Measures}

Following is a description of the measures employed in this study, in the order of their presentation to participants.

1) Academic stressors. Based on items adapted from Zeidner's (1992) Student Stress Inventory, participants were asked to select the most salient source of academic stress experienced during the past academic year, from a list of 16 potentially stressful academic events. These stressors assessed several distinct categories of academic stress, including: coursework (e.g.,
Table 1.

Means, SDs and frequency distributions of demographics, by cultural group.

\begin{tabular}{lccccc}
\hline \multicolumn{4}{c}{ Arab } & \multicolumn{2}{c}{ Jewish } \\
\hline & M & SD & M & SD & t-test \\
\hline Age & 23.83 & 4.23 & 27.44 & 3.98 & $10.06^{* *}$ \\
$\begin{array}{l}\text { Father education } \\
\text { school years }\end{array}$ & 11.31 & 4.21 & 13.52 & 3.50 & $6.50^{* *}$ \\
$\begin{array}{l}\text { Economic status } \\
\text { assessed }\end{array}$ & 2.54 & .97 & 2.76 & .99 & $2.57^{*}$ \\
$\begin{array}{l}\text { Health status } \\
\text { assessed }\end{array}$ & 1.51 & .69 & 1.63 & .74 & 1.91 \\
& & & & & Chi-Squaree \\
$\begin{array}{l}\text { Gender men } \\
\text { Family status single }\end{array}$ & 175 & $74.8 \%$ & 167 & $57.0 \%$ & $18.07^{* *}$ \\
$\begin{array}{l}\text { Student study level } \\
\text { undergraduates }\end{array}$ & 199 & $85.0 \%$ & 207 & $71.6 \%$ & $13.40^{* *}$ \\
\hline
\end{tabular}

Note: ${ }^{*} p<.01 ;{ }^{* *} p<.0001$; economic and health status scale: $1=$ very good; $5=$ not good at all.

"unreasonable course requirements"), evaluations and academic performance (e.g., "giving an oral presentation before the class"), academic environment (e.g., "difficulty in finding academic materials for course"), overload and time pressures ("not meeting deadlines for paper submission"), and social/interpersonal concerns (e.g., "interpersonal tensions with other students"). Students marked the most significant stressor recently experienced, and were asked to relate to the particular stressor they identified when responding to the remaining measures.

2) Stress Appraisal. Following Ben-Zur et al. (2005), students were asked to appraise the stressful academic events they chose with respect to perceived: threat, loss, negativity, challenge, and control $(1=$ not at all; $5=$ to a great extent $)$. Based on exploratory factor analysis, a stress appraisal subscale was formed; each of the first three scale items loaded at least .70 on the stress target factor, which accounted for $38 \%$ of the common scale variance. The challenge factor was not used due to poor psychometric attributes ${ }^{1}$.

3) Coping strategies were assessed via a brief 18 -item scale, based on the Hebrew version (Zeidner \& Ben-Zur, 1994) of Carver et al.'s COPE Scale (Carver et al., 1989). The original COPE consists of 60 items designed to assess 15 coping subscales, with four items per subscale. The present study assessed only 9 of these coping strategies, with two items assessing each strategy. Participants were asked to rate the extent $(0=$ not at all; $3=$ a great deal) to which they used each of the strategies (e.g., "I make a plan of action", "I let my feelings out", "I pretend that it has not happened") in coping with the academic stressor they chose. The following three coping scales were constructed based on a second order factor analysis, applied to subscale sums (Carver et al., 1989). a) Problem-focused coping (active coping, planning, suppression of competing activeties), accounting for $24 \%$ of the common factor variance; b) Emotion/support coping (instrumental support, emotional support, ventilation), accounting for $22 \%$ of the common factor variance; and c) Avoidance coping (mental disengagement, behavioral disengagement, denial), accounting for $24.12 \%$ of

${ }^{1}$ It should be noted that Arab and Jewish students did not differ on the challenge score $(t<1)$. 
the common factor variance.

4) Negative affect. The 20 -item Hebrew version (Ben-Zur, 2002) of Watson, Clark, and Tellegen's (1988) Positive and Negative Affect Schedule (PANAS) was employed to assess affective reactions. Respondents were asked to use each of the affective adjectives (e.g., "enthusiastic", "hostile"), on the scale to describe how they felt with respect to the academic stressor they selected, along a five-point scale $(1=$ not at all, $5=$ to a great extent). The scale is comprised of two 10 -item factoriallyderived subscales, i.e., positive affect and negative affect. These two subscales showed high internal reliabilities $(.84-.90)$ and high concurrent validity (Watson et al., 1988). Factor analysis applied to the 20 items in the present study also corroborated the two-factor structure, i.e., negative and positive affect, accounting for about $20 \%$ of the variance. Given our focus on stress-related emotions, only the negative affect scale was included in the present study.

5) Risk-taking behaviors. Based on risk items used by Hirschberger et al. (2000) participants were asked to rate $(0=$ not at all; $4=\mathrm{a}$ lot) the extent of occurrence of each of six risky behaviors during the period in which the stressful event occurred (e.g., "driving faster than usual"). The reliability of this 6 -item scale in the present study was .83 for the Arab students and .68 for their Jewish counterparts. The items' ratings were summed up to create a general risk taking scores.

6) Social desirability. The Hebrew adaptation (Ben-Zur, 2002) of the 8-item Social Desirability Questionnaire (Crowne \& Marlowe, 1964) was employed to control for potential social desirability in responding to the self-report personal measures. The scale showed satisfactory reliability values among Israelis $($ alpha $=.71$, Ben-Zur, 2012). A high score reflects higher levels of social desirability.

\section{Results}

\section{Preliminary Analysis}

As may be recalled, students were asked to select the most salient source of academic stress experienced during the ongoing academic year from among 16 available options (or add a stressor of their own in the event that none of the available options were relevant). Whereas no significant gender group response distributions were observed, response distributions of the academic stressors varied by cultural group, $\chi^{2}(16)=51.17$, $p<.001$, with a moderate relationship observed between cul- ture and response distribution \{Cramer's $\mathrm{V}=.31, p<.001\}$.

Although there were significant differences in response distributions by culture, a common set of salient stressors was identified by both Jewish and Arab students. Thus, at least 5\% of both Arab and Jewish students chose the following academic stimuli as being particularly stressful: a) conflict between work and study demands (Jewish $=25 \%$; Arab $=11 \%)$ ); b) overload in course assignments (Jewish $=9 \%$, Arab $=9 \%$ ); c) receiving a lower grade than expected on an important exam (Jewish = $15 \%$; Arab $=19 \%)$; d) taking a required course that was boring/frustrating (Jewish $=7 \%$; Arab $=9 \%$ ); e) difficulty in meeting deadlines for submission of course papers (Jewish $=$ $8 \% ;$ Arab $=11 \%)$; and $\mathrm{f}$ ) need to take a make-up exam due to failing grade (Jewish $=5 \%$; Arab $=12 \%)$.

\section{Test for Culture X Gender Effects}

As shown in Table 2, Arab students were significantly higher than their Jewish counterparts in perceived stress, the use of all three coping strategies (i.e., problem-focused, emotion/ support, avoidance), negative affect, risk taking, and social desirability. The following analyses were conducted to assess these differences while controlling for demographic variables and social desirability.

A 2 (Culture: Arabs vs Jews) $\times 2$ (Gender: Men vs Women) Multivariate Analysis of Covariance (MANOVA) was conducted on stress appraisals, three coping scales, negative affect and risky behavior, controlling for background variables (age, father education, economic status, family status, academic status and social desirability). This analysis showed significant effects for culture $[\Lambda=.92, \mathrm{~F}(6,486)=6.96, p<.001]$ and gender $[\Lambda=.93, \mathrm{~F}(6,486)=6.34, p<.001]$, but no significant Culture by Gender interaction $(\mathrm{F}<1)$. Significant culture effects were found for most of the research variables: perceived stress $\left[\mathrm{F}(1,491)=4.40, p<.05, \eta_{p}^{2}=.01\right]$, problem-focused coping $\left[\mathrm{F}(1,491)=5.71, p=.01, \eta_{p}^{2}=.01\right]$, avoidance $[\mathrm{F}$ $\left.(1,491)=28.40, p<.001, \eta_{p}^{2}=.06\right]$, negative affect $[\mathrm{F}(1,491)$ $\left.=11.87, p<.001, \eta_{p}^{2}=.02\right]$, and risk taking $[\mathrm{F}(1,491)=4.88$, $\left.p<.05, \eta_{p}^{2}=.01\right]$. Gender effects were observed for problemfocused coping $\left[\mathrm{F}(1,491)=4.87, p<.05, \eta_{p}^{2}=.01\right]$, emotion/support coping $\left[\mathrm{F}(1,491)=24.54, p<.001, \eta_{p}^{2}=.05\right]$, negative affect $\left[\mathrm{F}(1,491)=7.08, p<.01, \eta_{p}^{2}=.01\right]$, and risky behavior $\left[\mathrm{F}(1,491)=5.06, p<.05, \eta_{p}^{2}=.01\right]$. Women were higher than men on problem-focused and emotion/support coping and negative affect but lower than men on risky behavior.

Table 2.

Descriptive statistics for Arab and Jewish students on key measures: means, SDs and alpha coefficients.

\begin{tabular}{|c|c|c|c|c|c|c|c|}
\hline \multirow[b]{2}{*}{ Variables } & \multicolumn{3}{|c|}{$\operatorname{Arab}(\mathrm{n}=234)$} & \multicolumn{2}{|c|}{ Jewish $(n=294)$} & \multirow[b]{2}{*}{$\alpha$} & \multirow[b]{2}{*}{ D scores } \\
\hline & M & $\mathrm{SD}$ & $\alpha$ & M & SD & & \\
\hline Stress appraisal & 2.86 & 1.00 & .73 & 2.62 & .92 & .65 & $.25^{*}$ \\
\hline Problem-focused coping & 2.11 & .59 & .78 & 1.98 & .70 & .80 & $.20^{*}$ \\
\hline Emotion/support coping & 1.72 & .65 & .72 & 1.60 & .74 & .69 & $.17^{*}$ \\
\hline Avoidance coping & 1.16 & .67 & .79 & .78 & .58 & .68 & $.61^{*}$ \\
\hline Negative affect & 2.86 & .81 & .87 & 2.57 & .81 & .87 & $.39^{*}$ \\
\hline Risk taking behavior & .39 & .57 & .83 & .28 & .42 & .68 & $.21^{*}$ \\
\hline Social desirability & 1.58 & .23 & .51 & 1.50 & .25 & .60 & $.33^{*}$ \\
\hline
\end{tabular}

Note: D represents Hedges' unbiased estimators of effect size; ' $m$ mean differences are statistically reliable at $p<.05$ and beyond. 


\section{Nexus of Relationships: Stress, Coping, and Outcomes}

Highly similar patterns of relationships among perceived stress, coping, and adaptive outcomes were found for Jewish and Arab students (see Table 3). Thus, in both cultural groups, perceived stress evoked by a meaningful academic stressor was also significantly and moderately related to negative affect, but less so to risky behavior. Furthermore, in both cultural groups, students who perceived the academic stressor as more stressful also used more emotion/support coping and avoidance coping. In addition emotion/support and avoidance coping with an academic stressor was significantly related to negative outcomes in both cultural groups. Overall, the criterion variables representing negative outcomes were predicted by a similar set of predictors in Jewish and Arab groups.

\section{Hypotheses Testing}

To test the research hypotheses, several multiple regressions were conducted. The first hypothesis was tested by hierarchical regressions in which problem-focused, emotion/support and avoidance coping were regressed, in turn, on background and then appraisals variable. The second hypothesis was tested by hierarchical regressions in which negative affect and risky behaviors were regressed, in three steps, on background and then appraisal and then coping variables. The first step included culture $(0=$ Jewish; $1=$ Arab), and controlled for age, father education, economic status, family status $(1=$ single; $2=$ married), academic status ( $1=$ undergraduate; $2=$ graduate $)$, gender ( 1 = male; 2 = female $)$, and social desirability.

Coping strategies. Table 4 presents three multiple regressions aimed at testing appraisals and coping associations, using the first step to assess demographic and background variables. As can be seen in the table, on Step 2, after controlling for demographic and background variables, perceived stress predicted high levels of both emotion/support coping, together with gender, and also predicted avoidance coping, together with culture. We also hypothesized that stress appraisals would be negatively related to problem-focused coping but no association was found between appraisals and problem-focused coping, which was predicted by culture and gender. Thus, hypothesis a) was confirmed in part, suggesting that students who felt highly stressed coped with less adaptive coping strategies.

Negative affect. Table 5 shows on the second step that nega

Table 3.

Pearson correlations of appraisals, coping, and adaptive outcomes among Arab and Jewish students.

\begin{tabular}{lccccccc}
\hline Variable & 1 & 2 & 3 & 4 & 5 & 6 & 7 \\
\hline 1. Stress appraisals & & -.08 & $.20^{*}$ & $.22^{*}$ & $.45^{*}$ & .13 & -.04 \\
2. Problem-focused coping & -.06 & & $.36^{*}$ & -.00 & .09 & .04 & .09 \\
3. Emotion/support coping & $.28^{*}$ & $.31^{*}$ & & $.39^{*}$ & $.39^{*}$ & $.28^{*}$ & .07 \\
4. Avoidance coping & $.33^{*}$ & $-.17^{*}$ & $.30^{*}$ & & $.28^{*}$ & $.43^{*}$ & .02 \\
5. Negative affect & $.47^{*}$ & .12 & $.54^{*}$ & $.33^{*}$ & & $.22^{*}$ & -.14 \\
6. Risk taking & $.21^{*}$ & -.09 & -.03 & $.25^{*}$ & $.22^{*}$ & & -.10 \\
7. Social desirability & -.02 & .06 & .00 & .01 & $-.16^{*}$ & -.11 & \\
\hline
\end{tabular}

Note: Arab students' data $(\mathrm{n}=234)$ are given above the diagonal, and Jewish students' data $(\mathrm{n}=294)$ are given below the diagonal; ${ }^{*} p<.01$.

Table 4.

Hierarchical regressions of coping strategies on culture, demographics and stress appraisals.

\begin{tabular}{|c|c|c|c|c|c|c|}
\hline \multirow[b]{2}{*}{ Variable } & \multicolumn{2}{|c|}{ Problem-focused } & \multicolumn{2}{|c|}{ Emotion/support } & \multicolumn{2}{|c|}{ Avoidance } \\
\hline & Step 1 & Step 2 & Step 1 & Step 2 & Step 1 & Step 2 \\
\hline Culture & $.12^{*}$ & $.13^{*}$ & .10 & .07 & $.27^{* * *}$ & $.24^{* * *}$ \\
\hline Age & .11 & .11 & .04 & .06 & -.00 & .01 \\
\hline Father education & -.02 & -.02 & .00 & -.02 & -.01 & -.02 \\
\hline Economic status & -.01 & -.01 & .03 & .04 & .05 & .06 \\
\hline Family status & .05 & .05 & -.02 & -.02 & -.02 & -.01 \\
\hline Academic status & -.04 & -.04 & .08 & .08 & -.08 & -.08 \\
\hline Gender & $.10^{*}$ & $.10^{*}$ & $.22^{* * *}$ & $.23^{* * *}$ & .02 & .02 \\
\hline Social desirability & .07 & .07 & .02 & .02 & -.01 & -.00 \\
\hline Multiple $\mathrm{R}^{2}$ & .04 & & .07 & & .09 & \\
\hline $\mathrm{F}(8,492)$ & $2.48^{* *}$ & & $4.39^{* * *}$ & & $6.14^{* * *}$ & \\
\hline Multiple $\mathrm{R}^{2}$ & & .04 & & .13 & & .16 \\
\hline $\mathrm{F}(9,491)$ & & $2.37^{* *}$ & & $8.28^{* * *}$ & & $10.58^{* * *}$ \\
\hline
\end{tabular}

Note: ${ }^{*} p \leq .05 .{ }^{* *} p \leq .01 .{ }^{* * *} p<.001$. Gender, men $=1$; women $=2$; family dummy $1:$ single $=0$; married and divorced/widowed $=1 ;$ dummy 2 : married $=0 ;$ single and divorced/widowed $=1$. 
Table 5.

Hierarchical regressions of negative affect and risk taking on culture, demographics, stress appraisals and coping measures.

\begin{tabular}{|c|c|c|c|c|c|c|}
\hline \multirow[t]{2}{*}{ Variable } & \multicolumn{3}{|c|}{ Negative affect } & \multicolumn{3}{|c|}{ Risk taking } \\
\hline & Step 1 & Step 2 & Step 3 & Step 1 & Step 2 & Step 3 \\
\hline Culture & $.18^{* * *}$ & $.12^{* *}$ & .07 & $.12^{*}$ & $.10^{*}$ & .01 \\
\hline Age & -.03 & -.01 & -.03 & .00 & .01 & .00 \\
\hline Father education & -.04 & -.06 & -.06 & -.02 & -.02 & -.02 \\
\hline Economic status & .00 & .01 & -.01 & .00 & .01 & -.01 \\
\hline Family status & -.07 & -.06 & -.05 & -.07 & -.07 & -.06 \\
\hline Academic status & .08 & .08 & .06 & -.03 & -.03 & -.01 \\
\hline Gender & $.12^{* *}$ & $.13^{* *}$ & .04 & $-.11^{*}$ & $-.11^{*}$ & $-.12^{* *}$ \\
\hline Social desirability & $-.16^{* * *}$ & $-.15^{* * *}$ & $-.16^{* * *}$ & $-.09^{*}$ & $-.09^{*}$ & $-.09^{*}$ \\
\hline Multiple $\mathrm{R}^{2}$ & .08 & & & .04 & & \\
\hline $\mathrm{F}(8,492)$ & $5.15^{* * *}$ & & & $2.82^{* *}$ & & \\
\hline Stress appraisals & & $.45^{* * *}$ & $.34^{* * *}$ & & $.15^{* * *}$ & .05 \\
\hline Multiple $\mathrm{R}^{2}$ & & .28 & & & .07 & \\
\hline $\mathrm{F}(9,491)$ & & $20.80^{* * *}$ & & & $3.78^{* * *}$ & \\
\hline Problem-focused Coping & & & .03 & & & .03 \\
\hline Emotion/support Coping & & & $.34^{* * *}$ & & & .02 \\
\hline Avoidance coping & & & $.11^{* *}$ & & & $.35^{* * *}$ \\
\hline Multiple $\mathrm{R}^{2}$ & & & .41 & & & .17 \\
\hline $\mathrm{F}(12,488)$ & & & $28.61^{* * *}$ & & & $8.45^{* * *}$ \\
\hline
\end{tabular}

Note: ${ }^{*} p<=.05 .{ }^{* *} p<=.01 .{ }^{* * *} p<.001$; ethnicity, Jews $=0 ;$ Arabs $=1$; family status, single $=1$; married $=2 ;$ academic status, undergraduates $=1$, graduates $=2$; Gender, $\operatorname{men}=1$; women $=2$.

tive affect was positively related to perceived stress, together with cultural group, gender and social desirability. On the third step perceived stress, emotion-focused coping and avoidance contributed significantly to this outcome together with social desirability, but problem-focused coping did not contribute to negative affect. Thus, hypothesis b) was confirmed: Students who felt more stressed and used less adaptive coping strategies also reported higher levels of negative emotional states.

Risk taking. As can be seen in Table 5, on the second step, perceived stress together with cultural group, gender, and social desirability predicted risk taking. On the third step, only three predictors in the predictor stock were significant, i.e., gender, social desirability, and avoidant coping. Thus, hypothesis b) was confirmed in part: students who used greater avoidant coping also engaged in greater risk taking behavior.

As for hypothesis c), the data reported above show that Arab students, compared with Jewish students, felt more stressed, used more coping strategies of all types and reported more negative affect and risk taking, thus confirming the hypothesis.

\section{Discussion}

This study examined students' perceptions, coping strategies, and emotional and behavioral reactions with respect to a personally meaningful academic stressor. In line with our hypotheses, based on the cognitive model of stress (Lazarus, 1999), students who reported more perceived stress, also used less adaptive coping strategies and reported higher levels of negative emotional states and higher levels of risk taking behaviors. Additionally, when compared to Jewish students, Arab students reported higher levels of perceived stress, as well as more intensive use of problem-focused, emotion-focused, and avoidance coping strategies, higher levels of negative affect, and a tendency towards greater risk taking behaviors.

\section{Appraisals, Coping and Outcomes}

The positive associations between perceived stress, emotion/ support and avoidance coping, and negative affect are in line with the transactional model of stress and coping (e.g., Lazarus \& Folkman, 1984), which suggests that primary appraisal of threat is a key factor in determining the cascade of emotional and behavioral outcomes following a stressful encounter (e.g., Ben-Zur et al., 2005; Major et al., 1998). In addition, the data regarding emotion/support and avoidance coping, and their associations with negative affect are in line with past research on coping in specific contexts: emotion-focused coping is found to be highly correlated with psychological distress among cancer patients (e.g., Ben-Zur, Gilbar, \& Lev, 2001; Carver \& Scheier, 1993), university students (e.g., Zeidner, 1995), and community residents during traumatic national events (e.g., Zeidner, 2007; Zeidner \& Ben-Zur, 1993). In contrast, problemfocused coping is not related to distress as measured by stateanxiety (e.g., Zeidner \& Ben-Zur, 1993). Thus, students who appraise an academic stressor as highly threatening also cope with maladaptive coping strategies with resulting detrimental outcomes.

Unlike past research, the present study also used risk taking as an outcome of the stress process, and found that following an academic stressor, students who reported more perceived stress 
and the use of avoidance coping reported a higher frequency of risky behaviors, which were correlated with negative mood. These data are congenial with studies in the literature suggesting that risky behaviors tend to be elevated following exposure to traumatic events (Ben-Zur \& Zeidner, 2009; Pat-Horenczyk et al., 2007; Schiff, 2006). Thus, the present study lends evidence for the effects of elevated threat on risk taking within everyday stressful events such as the case of students' academic stressful encounters. Furthermore, these findings are in line with the notion that traumatic and stressful events may strengthen the tendency toward risk taking through the use of avoidance coping (e.g., Ben-Zur \& Zeidner, 2009).

\section{Cultural Differences in Stress Appraisals, Coping and Adaptive Outcomes}

As noted, Arab students were more threatened from exposure to an academic stressor than their Jewish counterparts and also experienced greater stress reactions, on average, such as negative affect, and more maladaptive behaviors, such as risk taking. The psychological literature shows national differences in the perception of various stressors (Spector et al., 2002, 2004), the stress consequences (Glazer \& Beehr, 2005), and the strength of the relationship between the reported stressors and their outcomes (Schaufeli \& Janczur, 1994).

Arab students scored higher on all three categories of coping, problem-focused, emotion-focused, and avoidance, than their Jewish counterparts. These data are consistent with data provided by Somer et al. (2009) showing that Israeli Arabs report using a wider array of coping strategies (e.g., acceptance, avoidance, collaborative coping) in managing stress. This might arise out of greater demands, in that academic stress is assessed as being more stressful, as well as greater overall adversity. With respect to the latter, Israeli Arabs may need to call upon a wider range of coping strategies, including collectivist-collaborative strategies, because they may not have the same access to the overarching sources of social and cultural support that are readily available to their Jewish compatriots. Furthermore, our data indicating that Arab and Jewish students employ similar strategies in coping with an academic stressor are congenial with prior studies showing similar uses of coping strategies among different cultural groups (Braun-Lewnshon et al., 2011). In sum, our data are also consistent with a number of studies showing less favorable emotional and coping reactions of Arabs during periods of conflict (Johnson et al., 2009; Schiff et al., 2010; Somer et al., 2009).

\section{Gender Differences}

Consistent gender group differences were observed for both Jewish and Arab subgroups. These data showing higher mean levels of stress and negative emotions in woman compared to men are consistent with some prior research and various lines of evidence (Ben-Zur \& Zeidner, 2012; Zeidner, 1992) suggesting that women students will show higher mean levels of stress than men during college. Cross-cultural studies of evaluative anxiety have reported significantly higher levels of anxiety among females relative to males, both in Israel and abroad (see Zeidner, 1998, for a review).

\section{Advantages and Disadvantages of the Study}

The reader should keep a number of constraints in mind when considering the findings. First, both the design and the data were basically correlational. Thus, we assumed that perceived stress and coping were antecedents of negative affect, and risk taking. However, the reverse causal relation may be true, with maladaptive outcomes recursively impacting on coping strategies. Furthermore, this study used paper and pencil inventories, which may be biased by response sets and suffer from the perennial problem of common methods variance. The advantages of the present study are twofold: First, the analyses were based on a relatively sizable sample of Jewish and Arab students. Second, a social desirability measure, found to be higher on average among Arabs than among Jews, was used as a control variable in the analyses. Thus, the findings regarding cultural differences were observed even when social desirability was controlled.

\section{Conclusion and Applications}

The present study assessed appraisals and reactions to academic stressors by students from two cultural sectors: Jewish and Arab. The pattern of relationships between stress appraisals, coping and outcomes was similar for Jewish and Arab students, and in accord with the cognitive model of stress (Lazarus, 1999). The levels of stress, coping and outcomes differ between the two groups, showing that Arab students were more threatened by academic stressors, coped with a variety of coping modes, including higher levels of avoidance coping, and reacted with higher levels of negative affect and more risk taking.

This study compared only two cultural groups, Arabs and Jewish students, and it should be run on other cultural groups that present minorities in Western countries to assess the generalizability of the findings in other cultures. Specifically, the findings suggest, first, that Arab students (and maybe minority students elsewhere) may need more consultation and guidance upon entering the university. They may profit from workshops that explain the nature of higher education studies, the demands, stressors, and conflicts that can occur between students, and between students and their instructors and mentors as well as other staff members, and the type of strategies that can be used in order to cope effectively with these stressors. Furthermore, the study findings showed that in general stressful events, apart from leading to negative mood, may lead students to expose themselves to danger through substance abuse, speedy driving, etc. These data also call for consultation for all students, the aim of which is to make them aware and beware of the possible detrimental results of stressful events.

\section{REFERENCES}

Ben-Zur, H. (2012). Loneliness, optimism, and well-being among married, divorced and widowed individuals. The Journal of Psychology, 146, 23-36. doi:10.1080/00223980.2010.548414

Ben-Zur, H., Gilbar, O., \& Lev, S. (2001). Coping with breast cancer: Patient, spouse and dyadic models. Psychosomatic Medicine, 63, 32-39.

Ben-Zur, H., \& Debi, Z. (2005). Optimism, social comparisons and coping with vision loss in Israel. Journal of Visual Impairment and Blindness, 99, 151-164.

Ben-Zur, H., Rappaport, B., Ammar, R., \& Uretzky, G. (2000). Coping strategies, life style changes, and pessimism after open-heart surgery. Health and Social Work, 25, 201-209. doi:10.1093/hsw/25.3.201

Ben-Zur, H., Yagil, D., \& Oz, D. (2005). Coping strategies and leadership in the adaptation to social change: The Israeli kibbutz. Anxiety, Stress and Coping, 18, 87-103. doi:10.1080/10615800500093702 
Ben-Zur, H., \& Zeidner, M. (2009). Threat to life and risk-taking behaviors: A review of empirical findings and explanatory models. Personality and Social Psychology Review, 13, 109-128. doi: $10.1177 / 1088868308330104$

Ben-Zur, H., \& Zeidner, M. (2012). Gender differences in loss of psychological resources following experimentally-induced vicarious stress. Anxiety, Stress and Coping, 25, 457-475.

Carver, C. S., \& Scheier, M. (1993). Vigilant and avoidant coping in two patient groups. In H. W. Krohne (Ed.), Attention and avoidance (pp. 295-319). Seattle: Hogrefe \& Huber.

Carver, C. S., Scheier, M. F., \& Weintraub, J. K. (1989). Assessing coping strategies: A theoretically based approach. Journal of Personality and Social Psychology, 56, 267-283. doi:10.1037/0022-3514.56.2.267

CBS Press Release (2011). 63rd independence day-Approximately $7,746,000$ residents in the State of Israel. Central bureau of statistics, State of Israel. URL (last checked 3 October 2011). www.cbs.gov.il

Crowne, D. P., \& Marlowe, D. (1964). The approval motive: Studies in evaluative dependence. New York: Wiley.

Dwairy, M. (2004). Culturally sensitive education: Adapting self-oriented assertiveness training to minorities. Journal of Social Issues, 60, 423-436. doi:10.1111/j.0022-4537.2004.00114.x

Dwairy, M. (2006). Parenting styles and mental health of Arab gifted adolescents. The Gifted Child Quarterly, 48, 275-286. doi: $10.1177 / 001698620404800403$

Folkman, S., \& Lazarus, R. S. (1985). If it changes it must be a process: Study of emotion and coping during three stage of a college exam. Journal of Personality and Socia Psychology, 48, 150-170. doi:10.1037/0022-3514.48.1.150

Gaudreau, P., Blondin, J. P., \& Lapierre, A. M. (2002). Athletes' coping during a competition: Relationship of coping strategies with positive affect, negative affect, and performance-goal discrepancy. Psychology of Sport and Exercise, 3, 125-150. doi:10.1016/S1469-0292(01)00015-2

Gelhaar, T., Seiffge-Krenke, I., Borge, A., Cicognani, E., Cunha, M., Loncaric, D., Macek, P., Steinhausen, H.-C., \& Winkler Metzke, C. (2007). Adolescent coping with everyday stressors: a seven nation-study with youth from Central, Eastern, Southern and Northern Europe. European Journal of Developmental Ppsychology, 4, 129156. doi:10.1080/17405620600831564

Glazer, S., \& Beehr, T. A. (2005). Consistency of implications of three role stressors across four countries. Journal of Organizational Behavior, 26, 467-487. doi:10.1002/job.326

Habib, J. (2008). The Arab population in Israel: Selected educational, economic, health and social indicators. Brookdale Institute.

Hirschberger, G, Florian, V., Mikulincer, M., Goldenberg, J. L., \& Pyszczynski, T. (2002). Gender differences in the willingness to engage in risky behavior: A terror management perspective. Death Studies, 26, 117-141. doi:10.1080/074811802753455244

Johnson, R. J., Canetti, D., Palmieri, P. A., Galea, S., Varley, J., \& Hobfoll, S. E. (2009). A prospective study of risk and resilience factors associated with posttraumatic stress symptoms and depression symptoms among Jews and Arabs exposed to repeated acts of terrorism in Israel. Psychological Trauma: Theory, Research, Practice, and Policy, 1, 291-311. doi:10.1037/a0017586

Kamm, S. (2003). The Arab minority in Israel: Implications for the Middle East conflict. URL (last checked 3 October 2011).

http://www.ceps.be

Khamaisi, R. (2011). Arab society in Israel: Population, society, economy. Jerusalem: Van leer Jerusalem Institute, Hakibbutz Hameuchad Publishing House.

Lazarus, R. S. (1999). Stress and emotion: A new synthesis. London: Free Association Books.

Lazarus, R. S., \& Folkman, S. (1984). Stress, appraisal and coping. New York: Springer-Verlag.

Lowe, R., Norman, P., \& Bennett, P. (2000). Coping, emotion and perceived health following myocardial infarction: Concurrent and predictive associations. British Journal of Health Psychology, 5, 337-350. doi:10.1348/135910700168964

Major, B., Richards, C., Cooper, M. L., Cozzarelli, C., \& Zubek, J. (1998). Personal resilience, cognitive appraisals, and coping: An in- tegrative model of adjustment to abortion. Journal of Personality and Social Psychology, 74, 735-752. doi:10.1037/0022-3514.74.3.735

Ntoumanis, N., \& Biddle, S. J. H. (1998). The relationship of coping and its perceived effectiveness to positive and negative affect in sport. Personality and Individual Differences, 24, 773-788. doi:10.1016/S0191-8869(97)00240-7

Oyserman, D., Coon, H. M., \& Kemmelmeier, M. (2002). Rethinking individuals and collectivism. Psychological Bulletin, 128, 3-72. doi:10.1037/0033-2909.128.1.3

Pat-Horenczyk, R., Peled, O., Miron, T., Brom, D., Villa, Y., \& Chemtob, C. M. (2007). Risk-taking behaviors among Israeli adolescents exposed to recurrent terrorism: Provoking danger under continuous threat? American Journal of Psychiatry, 164, 66-72. doi:10.1176/appi.ajp.164.1.66

Penley, J. A., Tomaka, J., \& Wiebe, J. S. (2002). The association of coping to physical and psychological health outcomes: A meta-analytic review. Journal of Behavioral Medicine, 25, 551-603. doi:10.1023/A:1020641400589

Saklofske, D. H., Austin, E. J., Mastoras, S. M., Beaton, L., \& Osborne, S. E. (2012). Relationships of personality, affect, emotional intelligence and coping with Student stress and academic success: Different patterns of association for stress and success. Learning and Individual Differences, 22, 251-257. doi:10.1016/j.lindif.2011.02.010

Schaufeli, W. B., \& Janczur, B. (1994). Burnout among nurses: A Polish-Dutch comparison. Journal of Cross-Cultural Psychology, 25, 95-113. doi:10.1177/0022022194251006

Schiff, M. (2006) Living in the shadow of terrorism: Psychological distress and alcohol use among religious and non-religious adolescents in Jerusalem. Social Sciences \& Medicine, 62, 2301-2312. doi:10.1016/j.socscimed.2005.10.016

Schiff, M., Pat-Horenczyk, R., Benbenishty, R., Brom, D., Baum, N., \& Astor, R. A. (2010). Do adolescents know when they need help in the aftermath of war? Journal of Traumatic Stress, 23, 657-660. doi: $10.1002 /$ its. 20558

Spector, P. E., Cooper, C. L., \& Aguilar-Vafaie, M. E. (2002). A comparative study of perceived job stressor sources and job strain in American and Iranian managers. Applied Psychology: An International Review, 51, 446-457. doi:10.1111/1464-0597.00102

Spector, P. E., Cooper, C. L., Poelmans, S., Allen, T. D., O’Driscoll, M., Sanchez, J. I., Siu, O., Dewe, P., Hart, P., Lu, L., De-Moreas, L. F. R., Ostrognay, G. M., Sparks, K., Wong, P., \& Yu, S. (2004). A cross-national comparative study of work-family stressors, working hours, and well-being: China and Latin America vs. the Anglo world. Personnel Psychology, 57, 119-142. doi:10.1111/j.1744-6570.2004.tb02486.x

Struthers, C. W., Perry, R. P., \& Menec, V. H. (2000). An examination of the relationship among academic stress, coping, motivation, and performance in college. Research in Higher Education, 41, 581-592. doi:10.1023/A:1007094931292

Watson, D., Clark, L. A., \& Tellegen, A. (1988). Development and validation of brief measures of positive and negative affect: The PANAS scale. Journal of Personality and Social Psychology, 54, 1063-1070. doi:10.1037/0022-3514.54.6.1063

Zeidner, M. (1987). The validity of college admission indices for Jews and Arabs in Israel. Personality and Individual Differences, 8, 587589. doi:10.1016/0191-8869(87)90225-X

Zeidner, M. (1992). Sources of academic stress: The case of first year Jewish and Arab students in Israel. Higher Education, 24, 26-40. doi:10.1007/BF00138616

Zeidner, M. (1995). Coping with examination stress: Resources, strategies, outcomes. Anxiety, Stress and Coping, 8, 279-298. doi: $10.1080 / 10615809508249379$

Zeidner, M. (1998). Personality and Intelligence. In B. Nevo (Ed.), Human intelligence (Vol. 2, pp. 725-762). Ramat Aviv: Open University.

Zeidner, M. (2007). Anxiety and coping with community disasters: The Israeli experience. Journal of Research in Personality, 41, 213-220. doi:10.1016/j.jrp.2006.02.002

Zeidner, M., \& Ben-Zur, H. (1993). Coping with a national crisis: The Israeli experience with the threat of missile attacks. Personality and Individual Differences, 14, 209-224. 


\section{H. BEN-ZUR, M. ZEIDNER}

Zeidner, M., \& Ben-Zur, H. (1994). Individual differences in anxiety, coping, and post-traumatic stress in the aftermath of the Persian Gulf War. Personality and Individual Differences, 16, 459-476.

doi:10.1016/0191-8869(93)90191-5

Zeidner, M., \& Ben-Zur, H. (2012). Subjective well-being (SWB) and personal resources: A comparison of Jewish and Arab Students in
Israel. Haifa: University of Haifa.

Zeidner, M., \& Schwarzer, Ch. (1996). Perceptions of academic stress in first year Israeli and German college students. In Ch. Schwarzer et al. (Eds.), Stress, anxiety, and coping in academic settings (pp. 69 92). Tubingen: Francke-Verlag. 